\title{
Article \\ Strengthening Regenerated Cellulose Fibers Sourced from Recycled Cotton T-Shirt Using Glucaric Acid for Antiplasticization
}

\author{
Manik Chandra Biswas ${ }^{1, *} \mathbb{C}$, Ryan Dwyer ${ }^{1}$, Javier Jimenez ${ }^{1} \mathbb{D}$, Hsun-Cheng $\mathrm{Su}^{2}$ and Ericka Ford ${ }^{3, *}$ \\ 1 Department of Textile Engineering, Chemistry and Science, Wilson College of Textiles, \\ North Carolina State University, 1020 Main Campus Drive, Raleigh, NC 27695, USA; \\ rmdwyer@ncsu.edu (R.D.); jjjimene@ncsu.edu (J.J.) \\ 2 Research \& Innovation, Circ (formerly Tyton BioSciences), 300 Ringgold Industrial Pkwy, \\ Danville, VA 24540, USA; sean@circ.earth \\ 3 The Nonwovens Institute, Department of Textile Engineering, Chemistry and Science, \\ North Carolina State University, 1020 Main Campus Drive, Raleigh, NC 27695, USA \\ * Correspondence: mbiswas2@ncsu.edu (M.C.B.); enford@ncsu.edu (E.F.)
}

Citation: Biswas, M.C.; Dwyer, R.; Jimenez, J.; Su, H.-C.; Ford, E. Strengthening Regenerated Cellulose Fibers Sourced from Recycled Cotton T-Shirt Using Glucaric Acid for Antiplasticization. Polysaccharides 2021, 2, 138-153. https://doi.org/ $10.3390 /$ polysaccharides 2010010

Academic Editor: Hyun Chan Kim

Received: 14 January 2021

Accepted: 22 February 2021

Published: 4 March 2021

Publisher's Note: MDPI stays neutral with regard to jurisdictional claims in published maps and institutional affiliations.

Copyright: (c) 2021 by the authors. Licensee MDPI, Basel, Switzerland. This article is an open access article distributed under the terms and conditions of the Creative Commons Attribution (CC BY) license (https:// creativecommons.org/licenses/by/ $4.0 /)$.

\begin{abstract}
The recycling of cellulose from cotton textiles would minimize the use of virgin crop fibers, but recycled polymers are generally inferior in mechanical performance to those made from virgin resins. This challenge prompted the investigation of biobased additives that were capable of improving the mechanical properties of fibers by means of antiplasticizing additives. In this study, regenerated cellulose $(\mathrm{RC})$ fibers were spun from cellulose found in cotton T-shirts, and fibers were mechanically strengthened with glucaric acid (GA), a nontoxic product of fermentation. The recycled pulp was activated using aqueous sodium hydroxide and then followed by acid neutralization, prior to the direct dissolution in lithium chloride/ $N, N$-dimethylacetamide (LiCl/DMAc) at 3 wt.\% cellulose. At 10\% (w/w) GA, the tensile modulus and strength of regenerated cellulose from recycled cotton fibers increased five-fold in contrast to neat fibers without GA. The highest modulus and tenacity values of $664 \mathrm{cN} / \mathrm{dtex}$ and of $9.7 \mathrm{cN} / \mathrm{d}$ tex were reported for RC fibers containing GA.
\end{abstract}

Keywords: antiplasticization; recycled cotton T-shirt; regenerated cellulosic fiber; bio-based additives; structure-property relationship; post-consumer waste; sustainability; circular economy

\section{Introduction}

Global fiber production in 2018 was roughly 107 million metric tons and this amount will only grow as the world population increases [1]. Textile waste is expected to increase in proportion to the world's population, and "fast fashion" is a major progenitor of preconsumer waste during fabric production and post-consumer waste at the end of its service life. Estimates from the Ellen MacArthur Foundation show that less than 1\% of all clothing is recycled back into clothing, representing a loss of more than $\$ 100$ billion USD in materials each year [2]. For the purpose of minimizing the use of nonrenewable resources and capitalizing on the economic benefits of repurposing waste into value-added products, experts in the global textiles industry suggest creating circular economies by introducing textile waste as an alternative source of upcoming textile products.

Recycling has an integral role in making the textile industry circular and more sustainable. Opportunities exist in the conversion of polymers within textile fabrics into recycled fibers. Polyethylene terephthalate (PET) is non-biodegradable, but PET dominates the global synthetic fiber textile industry due to its functionality as a fabric and low production cost at high volumes [1,3]. Even so, there is a limited supply of petroleum for resin and the production of synthetic fiber, which provides further concern about the future availability of raw materials- and not just environmental pollution. The recycling of PET resins from existing products is deemed to be a sustainable approach to extracting PET feedstocks and 
waste management. The recycling of PET bottles can help to reduce the accumulation of synthetic plastics within local landfills and aquatic ecosystems. The waste accumulated from PET bottles in Europe rose from 0.2 to 1.3 Mt for over a decade beginning in 1998, but this only accounts to $40 \%$ of the bottles consumed [4]. Over $70 \%$ of the PET recycled worldwide is converted into fibers; $10 \%$ is converted into bottles; and $20 \%$ is used for other applications such as sheets and strapping tape [5]. However, the ever-growing supply of non-biodegradable waste presents a complication in the global effort to promote sustainability, which may require auxiliary solutions along with recycling PET. For instance, man-made fibers of regenerated cellulose (RC) are environmentally sustainable due to the ability to manufacture them from the cellulose recycled from cotton fabrics, while being compostable and able to degrade in aquatic environments [6].

Biomass recycling (i.e., the repurposing of agricultural feedstocks and waste into value-added products) is one strategy for reducing landfill waste. The US Department of Energy and corporations committed to greening industrial supply chains are interested in promoting the conversion of cellulose from dedicated energy crops, agricultural crop residues, and industrial wastes into value-added products that are competitive with those manufactured from nonrenewable petrochemicals [7]. The development and commercialization of RC fibers from alternative sources of biomass is driven by global concerns for environmental pollution, sustainable waste management, the depletion of fossil fuels, and lack of circularity in the textile economy.

As of 2017, RC fiber consumption comprised $<7 \%$ of the global market; nevertheless, the demand for RC fibers is increasing along with interest in manufacturing textiles from renewable resources. The RC fiber production process involves the complete dissolution of cellulosic materials with solvent to get homogeneous dope (e.g., cotton, bagasse, recycled dissolving pulp), the extrusion of the dissolved dope into fiber, and then the extraction of the solvent to regenerate cellulose into its finalized form. The manufacturing of RC fibers has been studied for more than 150 years; the commercialization of viscose rayon began with Courtalds Fibers [8]. Unfortunately, the state-of-the-art for rayon manufacturing employs the use of and later the generation of environmentally hazardous products; such as carbon sulfide $\left(\mathrm{CS}_{2}\right)$ and hydrogen sulfide $\left(\mathrm{H}_{2} \mathrm{~S}\right)$ during the regeneration process [9]. An alternative to derivative dissolution (e.g., indirect dissolution) by the viscose rayon method is the approach for the direct dissolution of cellulose. In this process, cellulosic pulp is dissolved by ionic liquids. A commercialized version of direct dissolution is the Lyocell method by Lenzing AG, which uses 4-methylmorpholine 4-oxide (NMMO) to directly dissolve cellulosic pulp without the use of intermediates for cellulose derivatization [10]. This process precludes the need for toxic chemicals and the generation of harmful byproducts, which ultimately implies a greener process for the recycling of materials [11]. Challenges associated with NMMO dissolution include costs associated with the purchase of NMMO and the development of highly efficient solvent recycling. As an alternative to $\mathrm{NMMO}$ technology, the $\mathrm{NaOH}$ / urea solvent system showed prominent results regarding similar fiber properties, but with lower production costs [10]. However, the complexity of dissolving cellulose pulp in this $\mathrm{NaOH}$ / urea solvent system at cryogenic temperatures stymies the commercialization of this wet-spinning technique.

Opposed to commercial thermoplastic polymers which are melt extruded directly into fibers, cellulose degrades before it melts at elevated temperatures. Therefore, cellulose must undergo complete dissolution before any repurposing of the polymer can take place. Prior to direct dissolution, cellulose pulp from ground cotton (GC) for example may undergo chemical activation with sodium hydroxide $(\mathrm{NaOH})$ - wherein structural modification of cellulose aids in solvent penetration $[12,13]$. Because of the highly organized crystal structure of cotton cellulose, $\mathrm{NaOH}$ treatments (termed mercerization) aid in the process of cellulose dissolution. Mercerization improves the rate of dissolution due to the conversion of native cellulose I to cellulose II, wherein the parallel alignment of cellulose polymers turns anti-parallel by means of disrupting interchain $\mathrm{H}$-bonding. Chemical activation with $\mathrm{NaOH}$ is thus useful in reducing the percent crystallinity of fibers. Therefore, the processes 
of mechanical and chemical activation that led up to regeneration are critical factors in determining the quality of cellulose dope for fiber spinning. Ideally, these processes should yield high weight fraction of dissolve cellulose from the starting pulp [14].

Studies on this topic have shown that the mechanical activation of cotton linters (i.e., short seed fibers that are often considered as waste) results in low molecular weight cellulose. The reuse of cellulose from textiles can cause the resulting RC fibers to exhibit poor mechanical properties. Jiang et al. noted that the degree of polymerization (DP) for viscose rayon, lyocell, and ionic liquid-cell (IL-cell) fibers had DP values of 300, 550, and 540, respectively; whereas the DP values of the cellulose dissolving pulps for these fibers were 450-550, 500-900, and 500-800, respectively [15]. It is evident that the molecular weight of recycled cotton is ultimately influenced by processes used for end-use.

Strength-enhancing additives may provide a means to offsetting the negative effects of molecular weight reduction when regenerating cellulosic fibers from sources of recycled pulp. But the tensile strength and modulus of films or fibers containing plasticizing additives were lower than those without the plasticizer. Plasticizers derived from lignocellulosic sources include glucaric acid, fumaric acid, sorbitol [16], and nonlignocellulosic sources include glycerol, urea; however, these additives will not strengthen the mechanical properties of polymeric films or fibers [17]. The use of antiplasticizing additives is one strategy for enhancing the mechanical properties of fibers without compromising their processability. Polymers modified with antiplasticizers were reported to exhibit less free volume and chain mobility at ambient temperature than those containing, plasticizer [18-20]. Polar moieties along these antiplasticizers make them compatible with bulk polymer through intermolecular bonding. The use of biobased antiplasticizers would also contribute to their sustainability. In 2020, Biswas et al. demonstrated the ability to antiplasticize wet spun cellulose acetate fibers using glucaric acid (GA) and its salts- such that the mechanical strength and modulus of treated fibers improved [21].

GA is derived from glucose sugars or the depolymerization of cellulosic polymers [16]. According to the US Department of Energy, GA is a highly ranked bioderivative, which has commercial use in cement, detergents, and combating corrosion. Further, GA has been used in the synthesis of bio-derived polyamides. The antiplasticizing property of GA has been attributed to its ability to engage in secondary bonding with the matrix polymer. In the case of poly (vinyl alcohol) (PVA) and cellulose acetate, in particularly, GA hydroxyl groups can engage in hydrogen bonding with the pendant hydroxyl groups along PVA and cellulose diacetate polymers as reported in [21,22].

GA interacts with matrix polymer due to its multifunctionality and ability to form intermolecular hydrogen bonds [20-22]. In contrast to cellulose diacetate, nonderivatized cellulose polymers have three hydroxyl groups per glucose monomer and the potential for intermolecular hydrogen bonding with more than one hydroxyl group per glucose monomer. Therefore, the authors expect GA to render noteworthy performance properties among the RC fibers derived from recycled sources of cellulose pulp.

The objective of this study is to demonstrate the feasibility of spinning RC fibers from recycled pulp while minimizing the losses in mechanical strength. The manufacture of $\mathrm{RC}$ fibers from recycled sources of cellulose is deemed a sustainable approach to enabling a more circular textile economy. In this study, RC fibers were wet spun from cotton pulp that was recycled from cotton T-shirts. Prior to the direct dissolution of cellulose in lithium chloride $/ N, N$-dimethylacetamide ( $\mathrm{LiCl} / \mathrm{DMAc}$ ), cellulose pulp was activated using aqueous sodium hydroxide and then followed by acid neutralization. Lastly, dissolved pulp was modified with $10 \%$ (weight/weight, $w / v$ ) GA to strengthen the fibers. The performance of these RC fibers is characterized in terms of their processing conditions, mechanical properties, and morphology. 


\section{Experimental Section}

\subsection{Materials and Methods}

Cotton fibers from recycled T-shirts were gifted by Circ, LLC. (Radford, VA, USA) in the form of dissolving pulp, having a degree of polymerization (DP) in the range of 400-600 DP. Lithium chloride $(\mathrm{LiCl}), \mathrm{N}, \mathrm{N}$-dimethylacetamide (DMAc), and sulfuric acid $\left(\mathrm{H}_{2} \mathrm{SO}_{4}\right)$ were purchased from Sigma Aldrich. $\mathrm{NaOH}$ pellets were purchased from VWR. White vinegar (of $5 \%$ weight/volume $(w / v)$ acetic acid, $\left.\mathrm{CH}_{3} \mathrm{CO}_{2} \mathrm{H}\right)$ was used. GA was obtained from Kalion Inc. All chemicals including deionized (DI) water were used as-received.

\subsection{Protocol for Fiber Spinning from Recycled T-Shirt}

\subsubsection{Activation of Cellulose Pulp}

Dissolving pulp was mechanically and chemically activated prior to dissolution. The process flowchart for activation is depicted in Figure 1. Mechanical activation constituted the milling of cotton pulp into a fine powder using a 20-mesh metal sieve (having $~ 840 \mu \mathrm{m}$ holes). Ground cotton (GC) pulp was oven-dried at $85^{\circ} \mathrm{C}$ for at least $4 \mathrm{~h}$ and later stored in a desiccator until further use.

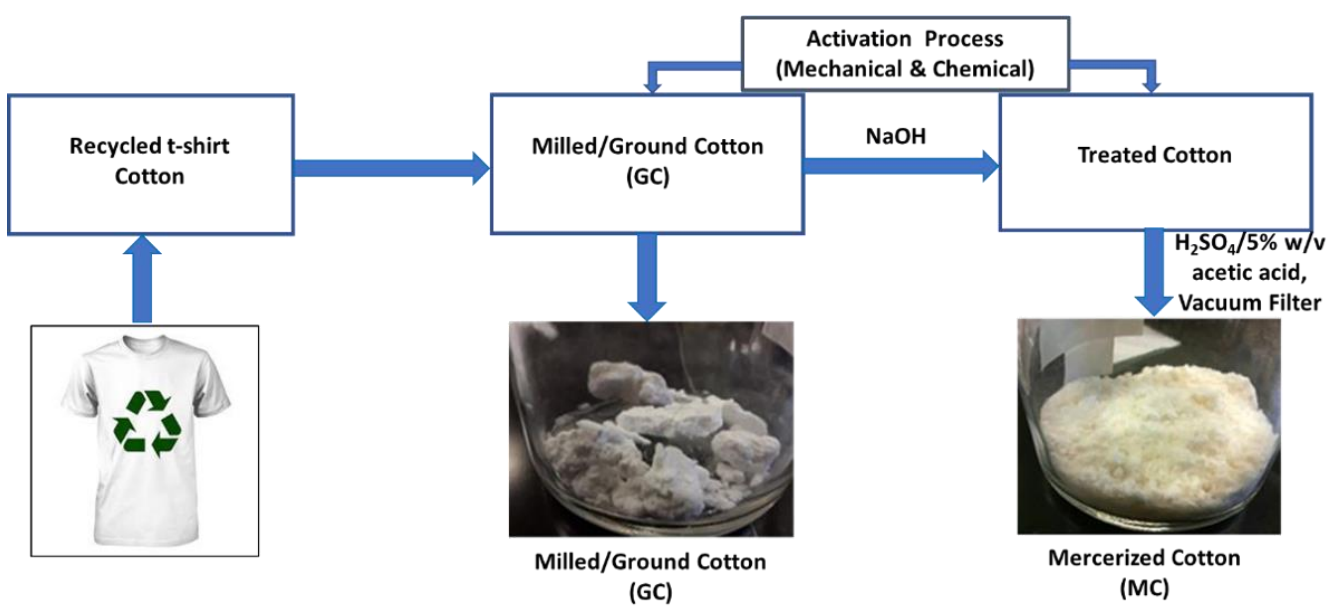

Figure 1. Flow chart of the mechanical and chemical activation of cellulose pulp from cotton t-shirts.

Total of $3 \mathrm{~g}$ samples of GC were mercerized in $60 \mathrm{~mL}$ of aqueous $\mathrm{NaOH}$ (at $20 \mathrm{w} / \mathrm{v} \%$ $\mathrm{NaOH}$ ) within a $250 \mathrm{~mL}$ Erlenmeyer flask under stirring at $250 \pm 10 \mathrm{rpm}$ for $5 \mathrm{~h}$ at room temperature $\left(\sim 23{ }^{\circ} \mathrm{C}\right)$. Afterwards, mercerized GC was filtered and neutralized from $\mathrm{pH} 12-13$ to 6-7 using a strong acid treatment of $2 \mathrm{~N} \mathrm{H}_{2} \mathrm{SO}_{4}$ (termed GCS) or weak acid treatment of $5 \% w / v \mathrm{CH}_{3} \mathrm{CO}_{2} \mathrm{H}$ (termed GCW). After acid treatment, GCS and GCW samples were washed thoroughly with deionized water.

\subsubsection{Dissolution Method}

About $3 \mathrm{wt}$ \% (weight percentage) of activated cellulose pulp was dissolved in $\mathrm{LiCl} / \mathrm{DMAc}($ at $8 \% w / v \mathrm{LiCl}$ ) in a $100 \mathrm{~mL}$ round-bottom flask. Spinning dopes of dissolved cellulose were heated to $127^{\circ} \mathrm{C}\left( \pm 3^{\circ} \mathrm{C}\right)$ with stirring at $250 \mathrm{rpm}$. The dissolution of cellulose pulp was complete among dopes that were quenched to room temperature with tap water under vigorous shaking (as shown in the centrifuged sample of Figure 2b). In contrast, undissolved cellulose was observed among the dopes that were gradually cooled to room temperature while under stirring (Figure 2a). GA induced spinning dopes were obtained as similar procedure where GA was added during cellulose dissolution. From our previous study on cellulose acetate (CA) and GA antiplasticization [21], an optimal ratio of $\sim 100: 2(w / w)$ between CA and GA was found, respectively. This weight ratio was converted to moles of hydroxyl groups (to normalize for hydrogen bonding) to get a 7:1 (mol -OH/mol -OH) between CA and GA, respectively. This hydroxyl molar ratio was used to calculate the mass of GA required for cellulose which was calculated to be 
$\sim 10 \mathrm{wt} \%$. Spinning dopes of $10 \mathrm{wt} . \%$ GA and GC neutralized with strong and weak acids were termed GA/GCS and GA/GCW, respectively.

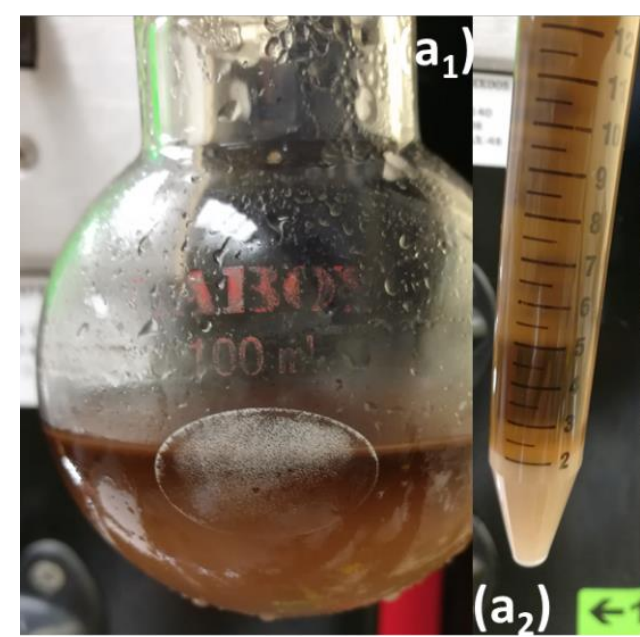

(a)

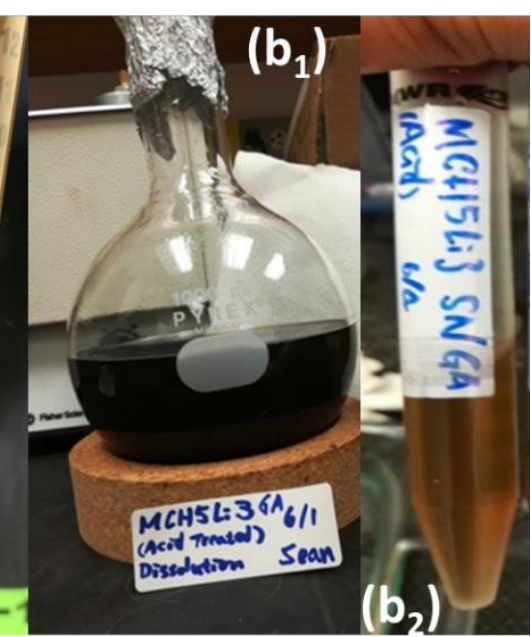

(b)

Figure 2. Cellulose spinning dopes of (a) partially dissolved GCW, and (b) completely dissolved GCS.

\subsubsection{Fiber Spinning}

The wet spinning of $R C$ is illustrated within the three steps of Figure 3. Step 1 involves the loading of spinning dope $(20 \mathrm{~mL})$ into a high-pressure steel syringe and the extrusion of fiber through a 22-gauge $(0.43 \mathrm{~mm}$ inner diameter) syringe needle. Solvent extraction from as-spun fiber occurred in the aqueous coagulation bath at room temperature. Afterwards, as-spun fibers of RC were collected onto a rotating winder. In step 2, as-spun fiber was soaked in tap water for $\sim 18 \mathrm{~h}$ at room temperature to further aid solvent removal. Step 3 of Figure 3 involved the batch drawing of aged, as-spun fiber from step 2 through two stages of silicon oil drawing. Each stage of thermal drawing occurred at consecutively higher temperatures. The draw ratio (DR) for each stage of as-spun fiber or thermal drawing was calculated by Equation (1); wherein, $V_{1}$ and $V_{2}$ represent the linear velocities of feed and take-up winders, respectively.

$$
\mathrm{DR}=\mathrm{V}_{2} / \mathrm{V}_{1}
$$

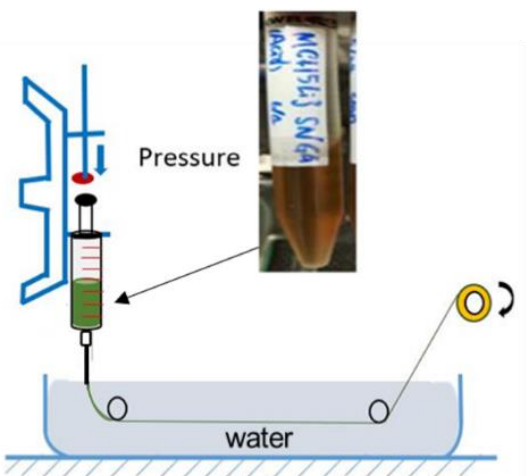

Step 1 As spun Fiber Formation

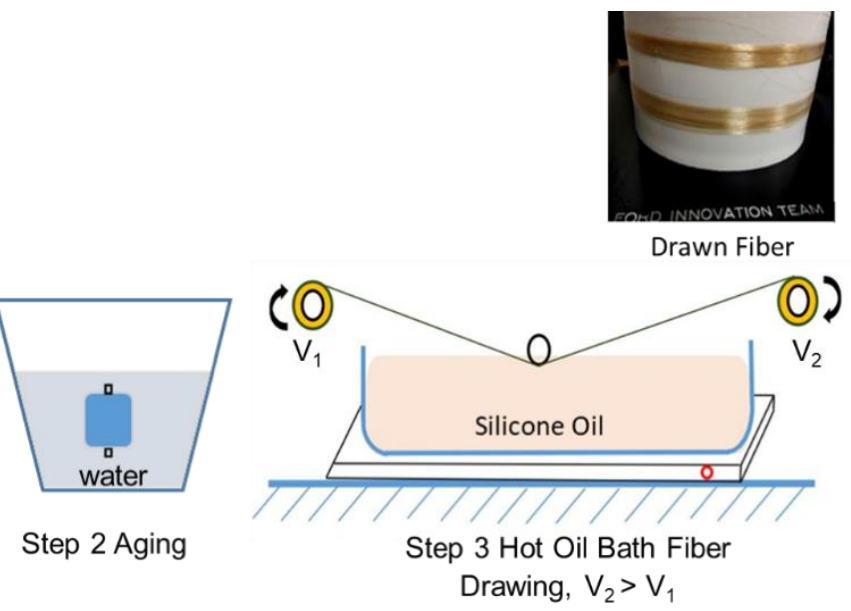

Figure 3. Schematic for the wet spinning of cellulose dopes into fiber through three processing steps: as-spun fiber formation (Step 1), as-spun fiber aging (Step 2), and hot silicon oil fiber drawing (Step 3). 


\subsection{Characterization of Activated Cellulose Pulp}

\subsubsection{X-ray Diffraction Analysis}

Diffractograms of wide-angle X-ray diffraction (WAXD) were used to analyze the microstructure of pulps before and after the chemical activation, and wet spun fibers (GCS, GA/GCS, and GA/GCW). Equatorial scans were performed on the PANalytical Empyrean $\mathrm{X}$-ray diffractometer at $45 \mathrm{kV}$ operating voltage, $40 \mathrm{~mA}$ current, with copper $\mathrm{K}-\alpha 1$ radiation at a wavelength of $1.54 \AA$, while using a fixed divergence slit. Scans were conducted over $5-60^{\circ} 2 \theta$.

\subsubsection{Fourier Transform Infrared (FTIR) Analysis}

The chemical analysis of activated pulps was performed on the NICOLET iS50 attenuated total reflection Fourier transform infrared (ATR-FTIR) spectrophotometer using 128 scans and $4 \mathrm{~cm}^{-1}$ spectral resolution. IR spectra in the $700-4000 \mathrm{~cm}^{-1}$ range were normalized to the $2921 \mathrm{~cm}^{-1} \mathrm{C}-\mathrm{H}$ stretching peak.

\subsection{Characterization of Drawn Fibers}

\subsubsection{Tensile Testing}

Fully drawn fibers were rinsed with isopropyl alcohol to remove the residue of drawing oil, dried at room temperature for at least $18 \mathrm{~h}$, and later conditioned at $25^{\circ} \mathrm{C}$ and $65 \%$ relative humidity until the time of mechanical testing (according to ASTM D1776). The tensile properties of RC fibers with and without GA were tested on the MTS-Q with a load cell of $4.45 \mathrm{~N}$ and TestXpert software for the data acquisition. Testing protocols were followed according to ASTM D3338 using a $25 \mathrm{~mm}$ gauge length and strain rate of $15 \mathrm{~mm} / \mathrm{min}$. At least 15 specimens per sample were tested to obtain specific stress, specific modulus, strain at break, and toughness (i.e., the energy absorbed up to the point of mechanical failure). Tensile force values were normalized with the linear density of fibers, $\mathrm{d}$, which was determined gravimetrically from the mass of $1 \mathrm{~m}$ of fiber. The wet tenacity of fibers was measured according to ASTM D3822 after immersion in water. Since the flexibility of fibers is not well defined by breaking-force or elongation at break, the ratio of breaking tenacity to loop tenacity in Equation (2) was used as an indication of flexibility, where $\mathrm{M}=$ breaking force and $\mathrm{L}=$ the linear density of the fiber specimen.

$$
\text { Loop breaking tenacity }=\frac{\mathrm{M}}{2 \mathrm{~L}}
$$

\subsubsection{Analysis of Fiber Microscopy}

The cross-sectional area (A) of fibers was determined gravimetrically from measurements of $d$ and the theoretical density of cellulose, $\rho$, using Equation (3)

$$
A=d / \rho
$$

Fiber cross-sections were imaged with the LEXT OSL4000 3D confocal laser microscope. Each sample of fiber was embedded in synthetic cork; then, the cork was thinly sliced perpendicular to the fiber length.

Fiber fracture tips from tensile testing were observed under the Verios-SEM to investigate the fiber morphology. Fractured samples were sputter coated with 60/40 (w/w) gold/palladium and imaged with a $2 \mathrm{kV}$ accelerating voltage.

\section{Results and Discussion}

\subsection{Microstructure of Chemically Activated Pulp}

The chemical activation of cellulose pulp involves $\mathrm{NaOH}$ mercerization and acid neutralization. In the case of Figure 4, mercerized pulp was neutralized with the strong acid $\mathrm{H}_{2} \mathrm{SO}_{4}$. Differences between the semicrystalline microstructures of strong acid neutralized pulp and untreated GC are shown among the diffractograms of Figure 4a,b. GC features the cellulose-I crystal form. Three diffraction peaks near $2 \theta$ values of $14.8^{\circ}, 16.4^{\circ}$, and $22.6^{\circ}$ 
are associated with the crystallographic planes of (110), (110), and (200), respectively, which are structurally characteristic of cellulose I (French, 2014). The acid neutralized pulp of GCS represents the transition from cellulose I to cellulose II. This transformation from native cellulose to a lower degree of crystallinity is evidenced by peak shifting to a higher wavenumber (3338 to $3442 \mathrm{~cm}^{-1}$ ) and the broadening of peaks (Figure 4c) [23,24]. Apart from the $-\mathrm{OH}$ vibration range (3000-3700 cm $\left.\mathrm{cm}^{-1}\right)$, a prominent peak was observed at $1429 \mathrm{~cm}^{-1}$ in cellulose I (Figure $4 c_{1}$ ) which disappeared in cellulose II after washing (Figure $4 c_{2}$ ) [23]. These changes in cellulose spectra were caused by the removal of the alkali and conformational changes in pulp as cellulose II formed [25]. Cellulose-I exhibits the parallel packing of hydroxymethyl groups $\left(-\mathrm{CH}_{2} \mathrm{OH}\right)$ between adjacent chains of cellulose (Figure 5).

As sodium ions $\left(\mathrm{Na}^{+}\right)$penetrate crystalline cellulose, its microstructure transforms into the anti-parallel packing of adjacent cellulose chains (i.e., cellulose-II packing of $-\mathrm{CH}_{2} \mathrm{OH}$ groups between polymer chains in Figure 5). The peaks associated with (110) and (110) shifted to $11.9^{\circ}$ and $20.1^{\circ}$, respectively, and the (200) shoulder peak moved to $21.8^{\circ}$. These changes are direct indicators of the transition of cellulose I to cellulose II upon treatment with $\mathrm{NaOH}$ solutions [26]. In turn, mercerized pulp in the form of cellulose-II is more susceptible to dissolution than cellulose-I.

According to IR spectra, inter- and intramolecular hydrogen bonding between cellulose chains were disrupted by chemical activation, which resulted in a transformation from cellulose-I to -II (Figures 4c and 5) [27,28]. Broadening of the -OH stretching peak (in the range of $3000-3600 \mathrm{~cm}^{-1}$ ) toward higher frequencies indicates the loss of crystalline order after chemical activation, as shown for GCS. This is consistent with the transition of cellulose I to cellulose II by WAXD analysis. The -OH peak was used to investigate secondary hydrogen bonding.
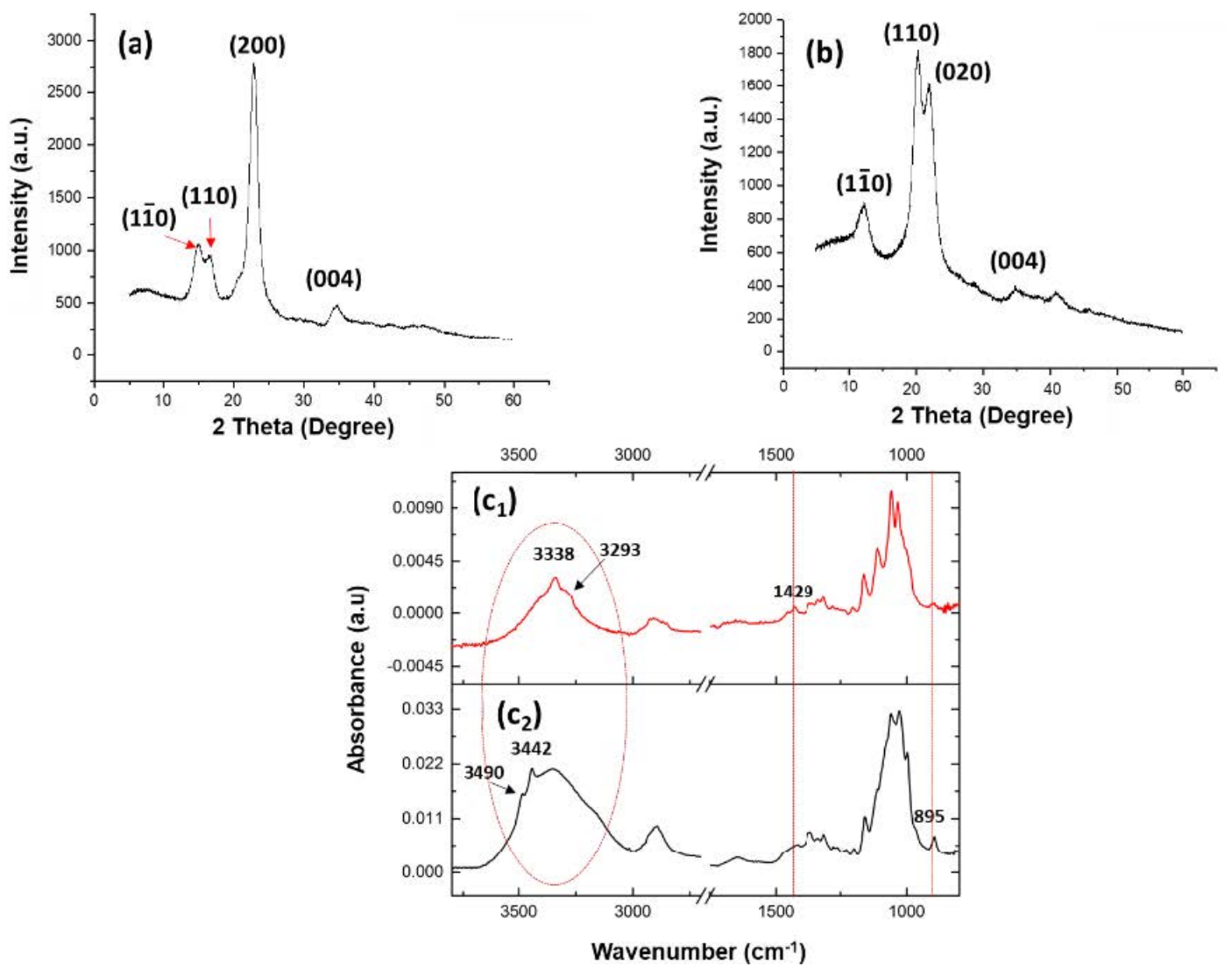

Figure 4. X-ray diffraction patterns of (a) GC pulp and (b) GCS pulp is shown along with the FTIR spectra of ( $\left.\mathbf{c}_{1}\right)$ GC pulp and $\left(\mathbf{c}_{2}\right)$ GCS pulp. 


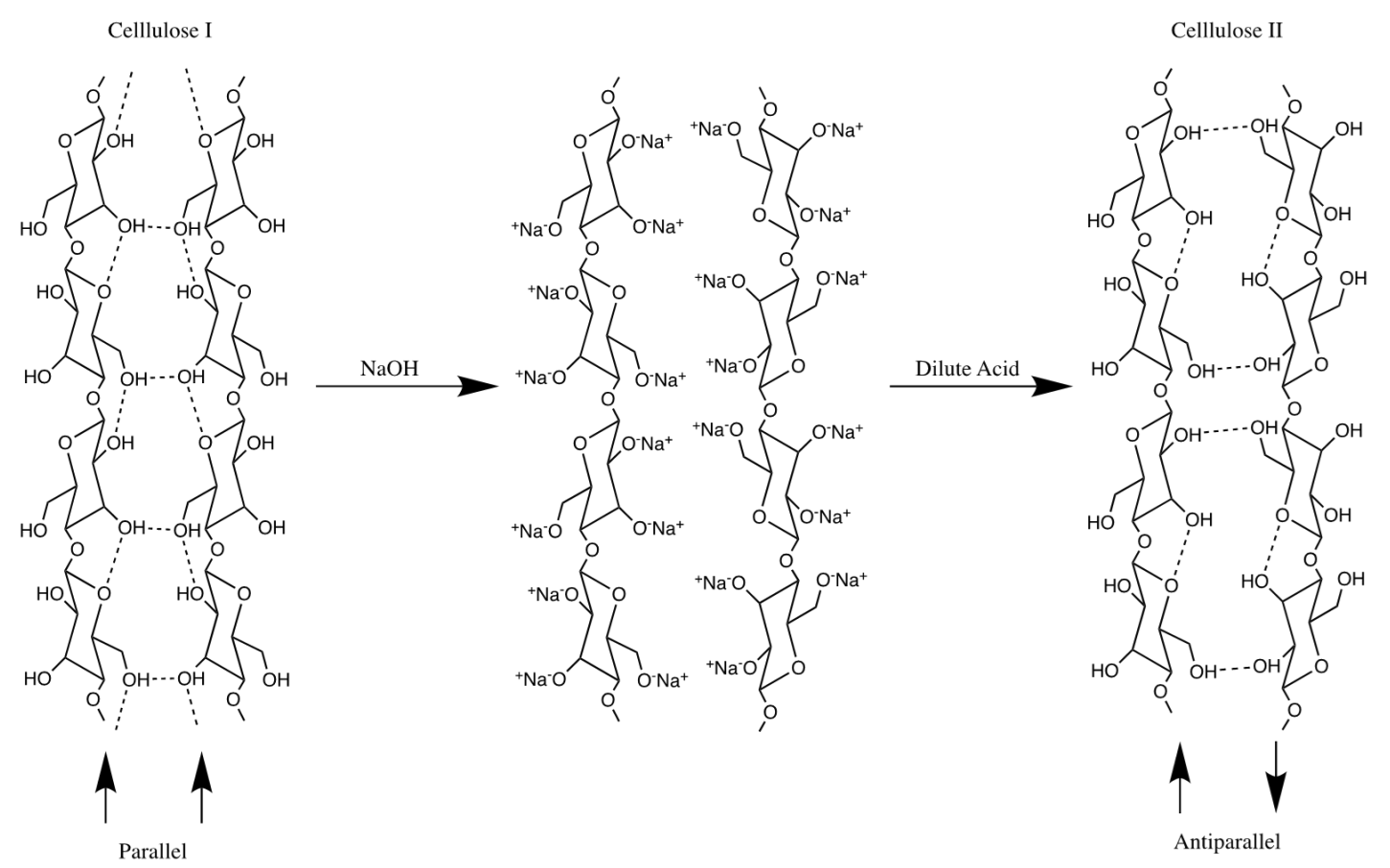

Figure 5. Transformation of cellulose I to cellulose II.

\subsection{Acid Neutralization on the Dissolution of Mercerized Pulp}

Weak and strong acid treatments for neutralizing cellulose pulps were tested against solvent dissolution. The control sample of GC was only treated with mechanical grinding prior to dissolution in DMAc/LiCl. Centrifuged samples of the GCW spinning dope show significantly higher amounts of undissolved pulp (Figure 2a) than those treated with $\mathrm{NaOH}$ and acid rinsed pulp (Figure $2 \mathrm{~b}$ ). At similar conditions, $\mathrm{H}_{2} \mathrm{SO}_{4}$ neutralization greatly improved the dissolution of cellulose pulp, as observed by the complete dissolution of GCS versus $\mathrm{GCW}$ (Figure $2 \mathrm{~b}$ ). $\mathrm{H}_{2} \mathrm{SO}_{4}$ neutralization may have improved pulp dissolution, because the strong acid could hydrolyze the cellulose versus the weak acid- thereby reducing the DP of the polymer chains $[29,30]$. These lower DP chains of cellulose could allow for a higher concentration of dissolved cellulose in $\mathrm{DMAc} / \mathrm{LiCl}$ [31]. Homogeneous dopes of dissolved pulp were later spun into fiber and their mechanical properties tested. Nevertheless, differences between the concentration of dissolved pulp among these samples could affect the tenacity of the resulting fibers.

\subsection{Effect of $G A$ on $R C$ Wet Spinning}

The effect of GA on the wet-spinning of cellulose dissolved from activated pulps was characterized by differences in fiber draw ratio and temperature settings for fiber drawing (as shown in Table 1). Thermal drawing conditions were identified by the ability to continuously spin fiber at the highest value of draw ratio. The addition of GA to spinning dopes induced higher draw ratios among as-spun fiber. The total draw ratio of cellulosic fibers increased from $2.5 \times$ to $6.5 \times$ with the addition of GA. The higher drawability of GA/GCS fibers implies that polymer chains are more mobile in comparison to neat GCS fiber. Due to these overall higher draw ratios, GA-containing fibers were finer than the neat RC fiber of GCS. Further, cellulose chains exhibited mobility at higher temperatures of drawing. This behavior implies the crystalline relaxation temperature for thermal drawing occurs at higher temperatures in the presence of GA, which appears to behave as a rheology modifier. Lu et al. and Zhang et al. have reported that the sequential drawing of polymeric fibers gradually increases crystalline relaxation temperatures, which corresponds to higher chain mobility at elevated temperature of drawing [32-34]. Lu et al. also reported that the intercalation of GA among crystalline chains of PVA, as fiber draw ratios were greatly improved with additive, were responsible for PVA strengthening [22]. 
Table 1. Spinning and drawing conditions of RC fibers.

\begin{tabular}{|c|c|c|c|c|}
\hline \multicolumn{2}{|c|}{ Process Conditions } & \multicolumn{3}{|c|}{ Glucaric Acid } \\
\hline \multicolumn{2}{|c|}{ Additive Conc. } & $0.0 \%$ GCS & $10 \%$ GA/GCS & $10 \%$ GA/GCW \\
\hline \multicolumn{2}{|c|}{ As spun Draw Ratio (DR) } & 1.1 & 2.1 & 2.1 \\
\hline \multirow{2}{*}{ Stage 1 Drawing } & Oil Temp. ${ }^{\circ} \mathrm{C}$ & 65 & 110 & 110 \\
\hline & DR & 1.5 & 1.7 & 1.9 \\
\hline \multirow{2}{*}{ Stage 2 Drawing } & Oil Temp. ${ }^{\circ} \mathrm{C}$ & 100 & 120 & 120 \\
\hline & $\mathrm{DR}$ & 1.6 & 1.8 & 1.6 \\
\hline \multicolumn{2}{|c|}{ Total DR } & 2.6 & 6.5 & 6.4 \\
\hline \multicolumn{2}{|c|}{ Linear Density (dtex) } & 8.4 & 7.2 & 6.6 \\
\hline \multicolumn{2}{|c|}{ Effective Diameter $(\mu \mathrm{m})$} & 27 & 25 & 24 \\
\hline
\end{tabular}

\subsection{Effect of $G A$ on Mechanical Properties}

The mechanical properties of spun GCS fibers reveal the combined effects of pulp activation, GA addition, and parameters for fiber drawing. The properties reported include dry and wet mechanical testing in tension (in Figure 6 and Table 2) and loop testing (in Table 3). Overall, GA improved the specific modulus of dry fibers that were spun from both types of activated pulps (GCW and GCS) relative to neat GCS fibers. At 10\% GA, the highest modulus of $664 \mathrm{cN} /$ dtex and tenacity of $9.7 \mathrm{cN} /$ dtex were reported for GA/GCS (at 10\% GA in Table 2). This equates to $500 \%$ improvement in tensile modulus and $450 \%$ improvement in tenacity when compared to the neat GCS fibers shown in Table 2 . This can be ascribed to the higher values of total draw ratio, which generally improves polymer chains alignment and polymer crystallization while improving the fiber strength. It is noteworthy to mention that GA/GCS exhibited excellent mechanical properties that are comparable to natural and commercial RC fibers (Table 2). It showed tensile modulus $664 \mathrm{cN} / \mathrm{dtex}$ and tenacity $9.7 \mathrm{cN} / \mathrm{dtex}$ that are significantly higher compared to cotton, viscose rayon, and lyocell fibers.

Neat GC and GA/GCW fibers showed lower mechanical properties than GA/GCS. This can be attributed in part to these having lower concentrations of cellulose than the GA/GCS spinning dope. Higher values in mechanical strength can result among fibers spun from dopes containing higher concentrations of cellulose, because physical chain entanglements can contribute to fiber strengthening. Strong acid neutralization helped to complete cellulose dissolution; thus, allowing for a higher number of cellulose chains to be available for interaction with GA.
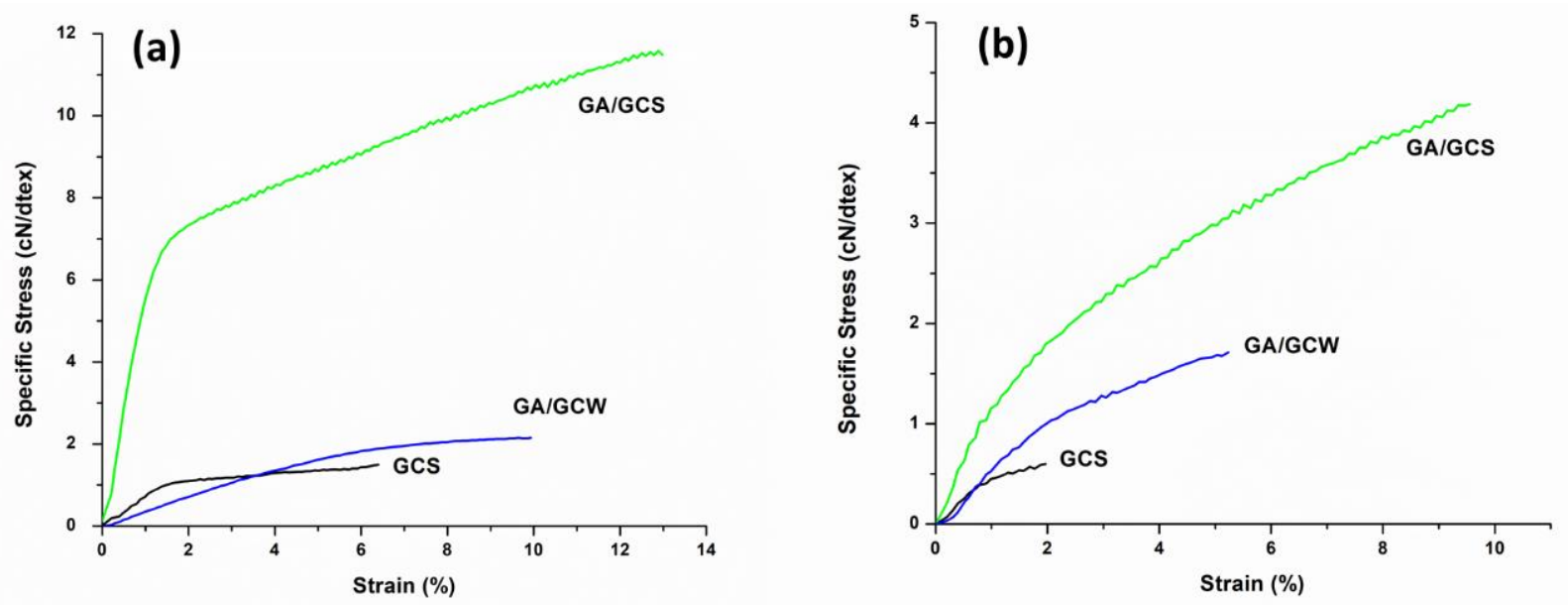

Figure 6. Specific stress versus strain curves for neat GCS and modified GCS fibers when (a) dry and (b) wet. 
Table 2. Mechanical properties of RC fibers and additive modified fibers.

\begin{tabular}{ccccccc}
\hline & \multicolumn{4}{c}{ Dry Condition } & \multicolumn{2}{c}{ Wet Condition } \\
\cline { 2 - 7 } Sample & $\begin{array}{c}\text { Specific Modulus } \\
\text { (cN/dtex) }\end{array}$ & $\begin{array}{c}\text { Tenacity } \\
\text { (cN/dtex) }\end{array}$ & $\begin{array}{c}\text { Strain at Break } \\
\mathbf{( \% )}\end{array}$ & $\begin{array}{c}\text { Toughness } \\
\text { J/g }\end{array}$ & $\begin{array}{c}\text { Specific Modulus } \\
\text { (cN/dtex) }\end{array}$ & $\begin{array}{c}\text { Tenacity } \\
\text { (cN/dtex) }\end{array}$ \\
\hline GCS & $114 \pm 3.20$ & $1.77 \pm 0.10$ & $6.5 \pm 1.0$ & $1.50 \pm 0.50$ & $70 \pm 2.80$ & $0.62 \pm 0.09$ \\
GA/GCS & $664 \pm 2.32$ & $9.70 \pm 0.11$ & $13 \pm 2.0$ & $6.20 \pm 2.16$ & $194 \pm 1.96$ & $4.40 \pm 0.13$ \\
GA/GCW & $81 \pm 3.30$ & $2.70 \pm 0.14$ & $10 \pm 2.0$ & $1.20 \pm 0.50$ & $26 \pm 2.62$ & $1.77 \pm 0.09$ \\
Cotton * & 53 & $1.87-3.77$ & - & - & - & $2.92-5.66$ \\
Flax * & 177 & $4.85-5.75$ & - & - & - & $5.82-6.89$ \\
Rayon * & 34 & 1.77 & - & - & - & 0.70 \\
Lyocell * & - & $4.3-5.9$ & - & - & 2.70 \\
\hline
\end{tabular}

* State-of-the-art for natural and regenerated fibers [35-38].

Table 3. Loop strength of CA/GA fibers.

\begin{tabular}{ccc}
\hline Sample & Specific Modulus (cN/dtex) & Tenacity (cN/dtex) \\
\hline GCS & $96 \pm 4.16$ & $0.009 \pm 0.001$ \\
GA/GCS & $596 \pm 6.33$ & $0.09 \pm 0.02$ \\
GA/GCW & $145 \pm 4.51$ & $0.02 \pm 0.005$ \\
\hline
\end{tabular}

The GA/GCS fiber exhibited higher toughness than the neat GCS fiber (Table 1). Figure 6a reveals high strain at break values of GA/GCS fiber than the neat GCS fiber. The GCS fiber was the weakest of all fibers with a low value of toughness. Plastic necking before failure was observed, but at much lower values of strain at break. Strain hardening was prevalent among dry GA/GCS fibers; but only plastic deformation was observed among the specific stress-strain curve of dry GA/GCW fiber (Figures 6 and 7).

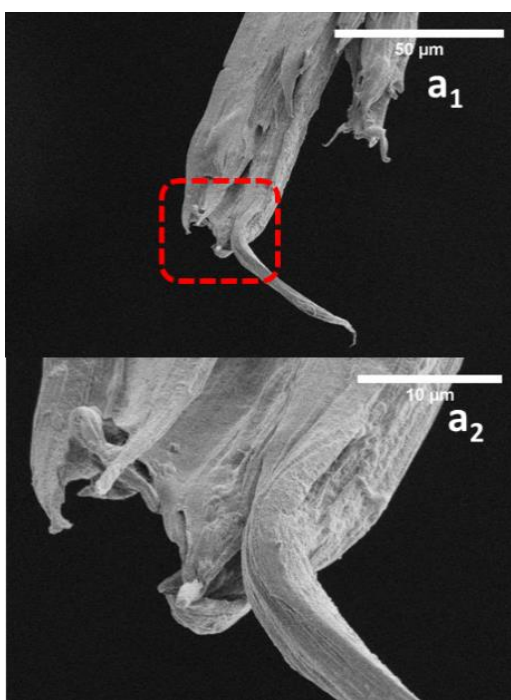

(a)

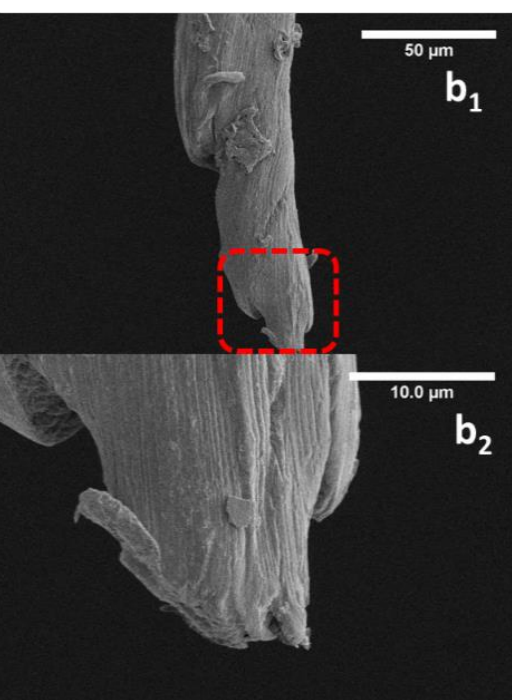

(b)

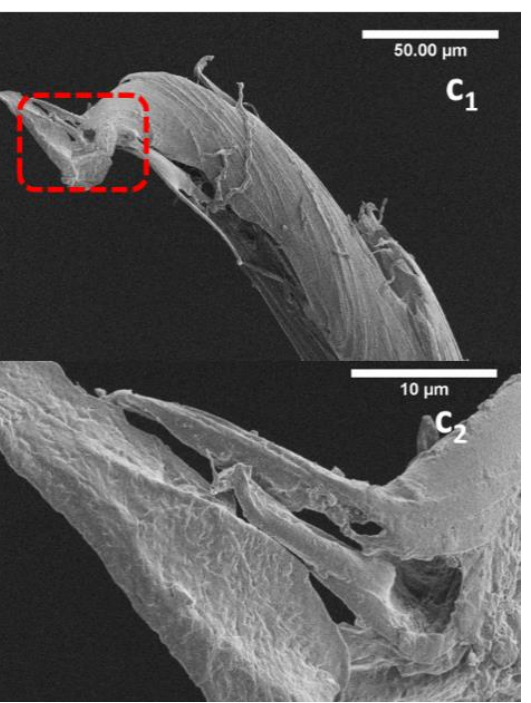

(c)

Figure 7. Fiber fracture tips of (a) neat GCS, (b) GA/GCW, and (c) GA/GCS were imaged using SEM at (1) low and (2) high resolution.

Micrographs in Figure 7a of the fracture tip from neat GCS fiber shows fibrils. Plastic failure and deformation in shear are noted by the twisting of macroscale fibrils relative to the fiber axes of GA/GCS and GA/GCW fibers (Figure 7b,c). The presence of GA between cellulose chains is attributed as the cause of these twisted fibrils upon deformation and the higher values of strain to failure. 
Water is known to reduce the mechanical properties of RC fibers, which is due in part to the disruption of hydrogen bonds and the saturation of amorphous polymer. Likewise, water immersion did reduce the mechanical strength of GCS- and GA-modified fibers. But GA modification did make the mechanical performance of RC fibers less sensitive to moisture upon immersed in water. The tenacity and modulus of GA-modified fibers were higher than that of neat GCS fiber (Figure $6 \mathrm{~b}$, Table 2). $45 \%$ of the tenacity for GA/GCS was retained after exposure to water in contrast to 35\% for neat GCS fiber (Table 2). Based on these results, GA appears to restrict the penetration of water within the fiber microstructure, which helps to preserve the wet strength of GA-modified fibers. This manuscript will take a more in-depth look at these cellulose-GA interactions using spectroscopy.

The loop configuration represents possible failure modes among fibers configured into woven, knitted, or nonwoven fabrics. The loop tenacity of GA-modified fibers is shown in Table 3. At 10\% GA, the loop strengths and specific modulus of GA/GCS fiber are ten-fold and six-fold higher, respectively, to the values corresponding to GCS fiber. Changes in chemical structure were investigated by IR to understand why the GA additive enhanced the mechanical strength.

\subsection{Understanding the Effect of GA Additives on Fiber Morphology}

The IR and WAXD analysis of RC fibers with and without GA was performed to understand chemical and structural differences between these fibers that could explain their mechanical performance (Figures 8 and 9). IR absorption bands between $3670-2800 \mathrm{~cm}^{-1}$ and $1700-700 \mathrm{~cm}^{-1}$ are of interest for this analysis. Quintessential IR peaks for RC include the vibrational stretching of $-\mathrm{OH}$ groups at $3371 \mathrm{~cm}^{-1}$, the vibration of absorbed moisture in cellulose at $1646 \mathrm{~cm}^{-1}, \mathrm{C}-\mathrm{O}$ stretching at $1261 \mathrm{~cm}^{-1}, \mathrm{C}-\mathrm{O}-\mathrm{C}$ stretching at $1025 \mathrm{~cm}^{-1}$, and $-\mathrm{C}-\mathrm{H}$ stretching (among $-\mathrm{CH}_{3}$ and $-\mathrm{CH}_{2}$ groups) at $2960-2850 \mathrm{~cm}^{-1}$ [39]. The dehydration of -OH groups can occur at elevated temperatures in the presence of strong acids [40]; this reaction can result in cis- $\mathrm{CH}=\mathrm{CH}$ - groups, as noted by absorbance at $802 \mathrm{~cm}^{-1}$. The $\mathrm{C}=\mathrm{O}$ ester group of GA has a strong vibration peak around $1724 \mathrm{~cm}^{-1}$, while the C-Oabsorption frequency is at $1090 \mathrm{~cm}^{-1}$ [41].

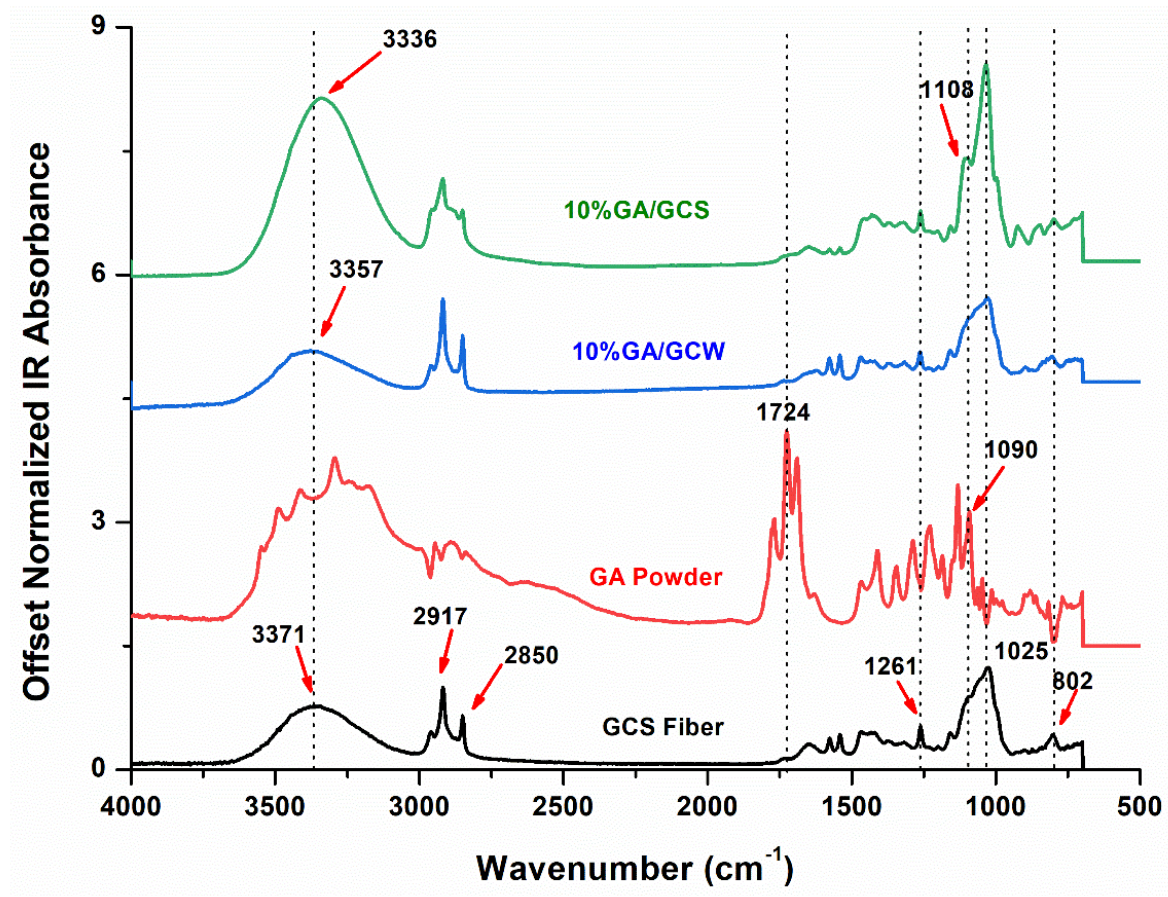

Figure 8. IR absorbance spectra of GCS and modified fibers. 


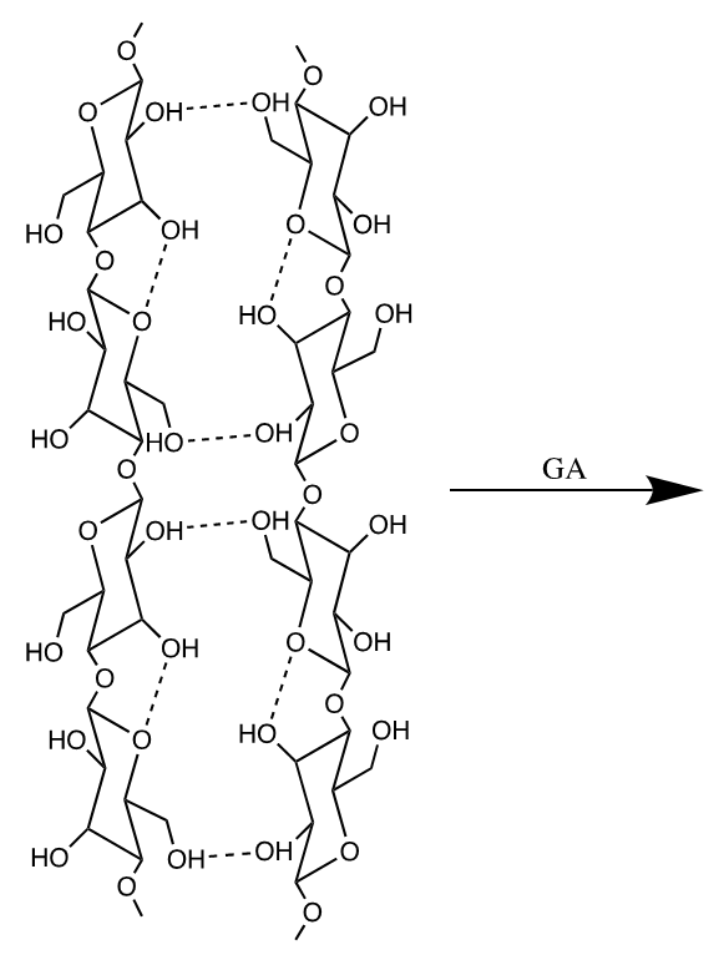

Cellulose Polymer Chains w/o GA

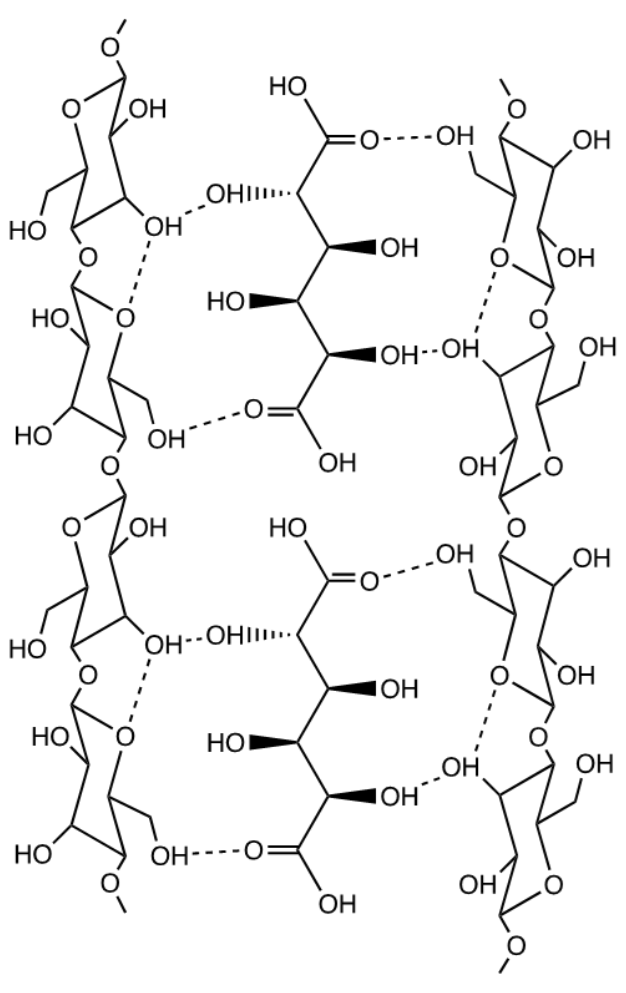

Cellulose Polymer Chains w/ GA

Figure 9. Schematic diagram of the bonding mechanism between GA and the cellulose chain.

The peak intensities for -OH groups $\left(3000-3700 \mathrm{~cm}^{-1}\right)$ were found significantly higher and narrower for GA/GCS fibers (Figure 8); these represent the mildest instances of alkaline hydrolysis and dehydration [42]. The new peak observed at $1108 \mathrm{~cm}^{-1}(\mathrm{C}=\mathrm{O})$ shoulder of C-O-C peak at $1025 \mathrm{~cm}^{-1}$ among fully drawn GA/GCS fiber. The added GA molecules can reside in amorphous polymer chains and interact with them. The high temperature drawing of fibers under tension influences GA co-crystallization and strain hardening among the GA-modified fibers. Further, GA/GCS was the strongest of the GA-modified RC fibers.

It is worth mentioning that the peak intensities for hydroxyl groups shifted to lower frequencies with the addition of GA (Figure 8). In comparison to the neat GCS fibers, the -OH peak for GA/GCS fiber shifted to $3336 \mathrm{~cm}^{-1}$ (versus the $3371 \mathrm{~cm}^{-1}$ for GCS $-\mathrm{OH}$ groups). This $-\mathrm{OH}$ shift can be attributed to strong, intermolecular hydrogen bonding between GA and cellulose chains. These lower frequencies for $-\mathrm{OH}$ absorbance suggest hydrogen bonding between $\mathrm{O} \cdots \mathrm{O}$ atoms over shorter distances, which is characteristic of secondary bonding (Figure 9). Lu et al., also found similar trends between GA and PVA -OH groups [21,22].

Antiplasticization is characterized by strong RC-GA interactions and conformational changes at noted by IR, Strong hydrogen bonds between cellulose chains and GA can stymie the moisture penetration of water molecules between cellulose chains. This results in GA-modified fibers being less susceptible to moisture and being able to retain more of their strength.

Diffraction patterns of cellulose pulp and RC fibers are in Figure 10. Characteristic peaks of cellulose I and cellulose II, as discussed in Section 3.1 are observed. In terms of fiber crystallinity, $X_{c}$, the regenerated fibers GA/GCS showed lower crystallinity in comparison to GC pulp with and without chemical activation by $\mathrm{NaOH}[43,44]$. Evidences of broadening and more intensity among the amorphous regions of cellulose chains were observed among the GA/GCS and GA/GCW fibers in comparison to pulps and neat GCS fiber (Figure 10). This behavior implies GA molecules are capable of interacting with 
cellulose hydroxyl groups as they insert themselves between cellulose chains, which results in the disruption of the cellulose II microstructure of RC fiber as noted by IR analysis. Cellulose II yields a more amorphous microstructure. This is also supported by previous studies reported in the literature [43-45]. Nonetheless, the tensile strength enhancement occurred due to hydrogen bonding between GA and cellulose polymer chains, chain alignment during high-temperature thermal drawing, and new crystal formation $\left(1108 \mathrm{~cm}^{-1}\right)$ at tension.

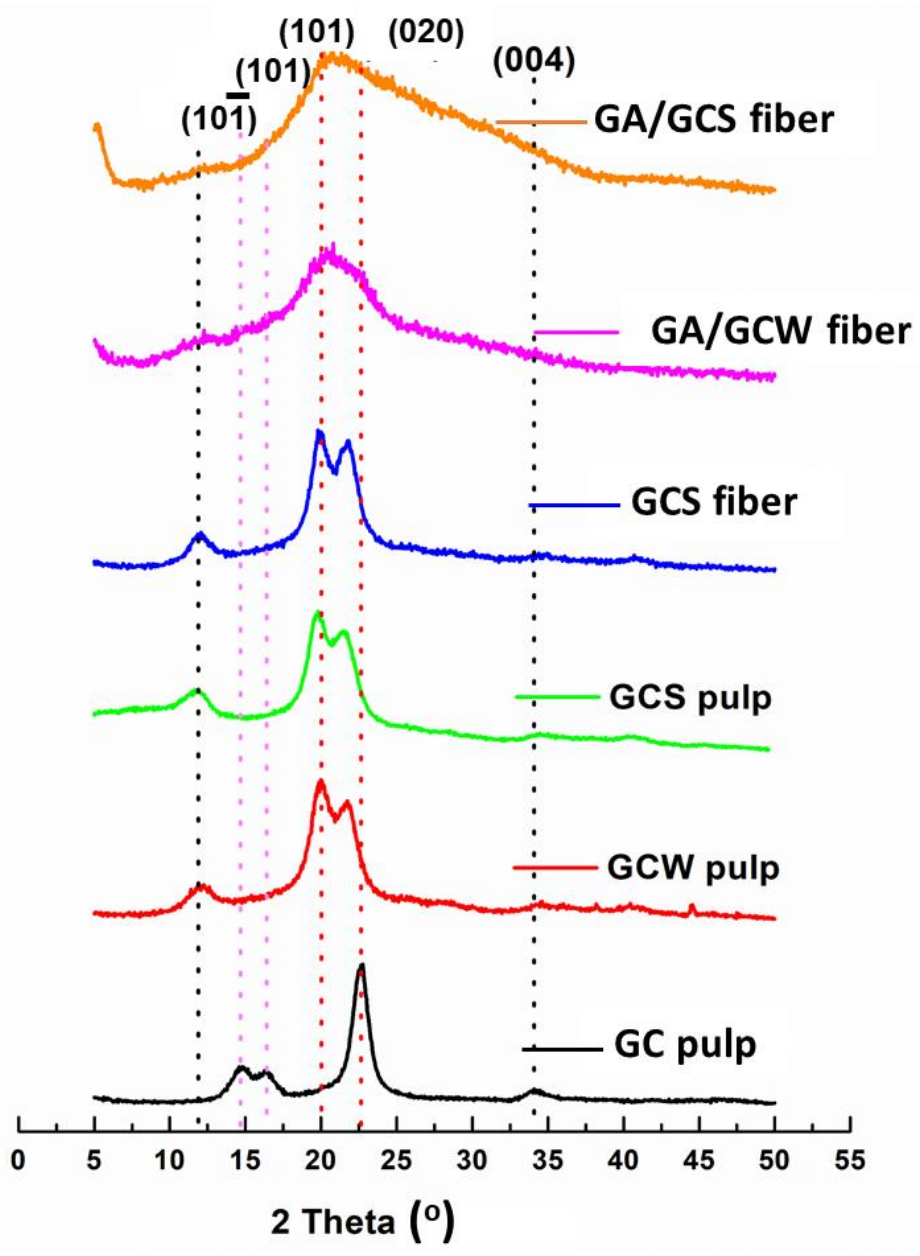

Figure 10. X-ray diffraction patterns for these samples are given: GC, GCW, and GCS pulp; GCS fiber; GA/GCW and GA/GCS fibers.

\section{Conclusions}

The post-consumer textile apparel market presents an opportunity and a challenge in the face of economic circularity. Antiplasticizers are well-known additives for improving the modulus of engineering plastics, but are less studied in the spinning of recycled cellulose. In contrast to plasticizers, the addition of antiplasticizers to regenerated fibers has the potential to expand their performance properties toward apparel or technical textile applications, even when recycled post-consumer waste or other sources of cellulose (such as agricultural residues) for fiber spinning are used. GA actually caused the mechanical performance of RC fibers spun from recycled cotton to exhibit properties comparable to that of natural cellulosic fibers. The state-of-the-art for natural and man-made fibers (such as cotton, rayon, and lyocell) have breaking tenacities between 2.7 and $9.7 \mathrm{cN} / \mathrm{dtex}$, specific modulus values of $81-664 \mathrm{cN} / \mathrm{dtex}$, and strain at break values of $10-13 \%$.

In conclusion, GA is deemed an antiplasticizer, because the rheology of solvent laden chains improved to allow for higher draw ratios among as-spun fiber and those drawn at elevated temperatures as the residual solvent is removed. The total draw ratio of 
cellulosic fibers increased from $2.5 \times$ to $6.5 \times$ with the addition of GA. Wet spun RC fibers modified with GA exhibited high mechanical properties (tensile modulus of $664 \mathrm{cN} / \mathrm{dtex}$ and tenacity of $9.7 \mathrm{cN} / \mathrm{dtex}$ ) in comparison to the control fiber without GA (tensile modulus of $114 \mathrm{cN} / \mathrm{dtex}$ and tenacity of $1.77 \mathrm{cN} / \mathrm{dtex}$ ). Hydrogen bonding between cellulose chains and GA was attributed with strengthening fibers, in particularly within the amorphous regions of cellulose.

Author Contributions: Conceptualization, E.F. and H.-C.S.; methodology, M.C.B., J.J., E.F.; validation, E.F. and H.-C.S.; formal analysis, M.C.B.; investigation, M.C.B., R.D., J.J. and H.-C.S.; resources, E.F., H.-C.S.; data curation, M.C.B., R.D., J.J.; writing-original draft preparation, M.C.B., R.D.; writingE.F., J.J., H.-C.S.; visualization, M.C.B., R.D., J.J.; supervision, E.F., H.-C.S.; project administration, E.F., H.-C.S.; funding acquisition, E.F. All authors have read and agreed to the published version of the manuscript.

Funding: Circ: (formerly Tyton BioSciences).

Institutional Review Board Statement: Not Applicable. Human Subjects not involved in this study.

Informed Consent Statement: Not Applicable. Human Subjects not involved in this study.

Data Availability Statement: Data is contained within the article.

Acknowledgments: Circ (formerly Tyton BioSciences) sponsored this research and donated cotton pulp from recycled T-shirts. Kalion, Inc. donated glucaric acid for this research. This work was performed in part at the Analytical Instrumentation Facilities (AIF) at North Carolina State University, which is supported by the state of North Carolina and the National Science Foundation (Award Number ECCS-1542015). AIF is a member of RTNN, a site in the National Nanotechnology Coordinated Infrastructure (NNCI).

Conflicts of Interest: This work is patent pending and under licensure. The authors claim conflict of financial interest based on the patent licensing arrangement for subject matter discussed in this manuscript.

$\begin{array}{ll}\text { Abbreviations } \\ \text { GA } & \text { Pure glucaric acid } \\ \text { GC } & \text { Unmercerized ground cotton cellulose pulp } \\ \text { GCS pulp } & \text { Strong acid treated cellulose pulp } \\ \text { GCW pulp } & \text { Weak acid treated cellulose pulp } \\ \text { GCS } & \text { Strong acid treated neat regenerated cellulose fibers } \\ \text { GA/GCS } & \text { Glucaric acid modified GCS regenerated cellulose fibers } \\ \text { GA/GCW } & \text { Glucaric acid modified GCW regenerated cellulose fibers }\end{array}$

\section{References}

1. Worley, D. Preferred Fiber Reports. 2018. Available online: https://textileexchange.org/2018-preferred-fiber-reports/ (accessed on 11 October 2020).

2. Circular Economy Reports \& Publications from the Ellen MacArthur Foundation"; EDT 2016. Available online: https://www. google.com/ (accessed on 11 October 2020).

3. Chakraborty, S.; Khatun, M.; Biswas, M.C. Influence of fiber surface morphology on the dyeing performance of polyester yarn. Researchgate 2020, 4, 117-125.

4. GLENZ 2007; Home: Plastics Europe. Available online: https://www.google.com/ (accessed on 11 October 2020).

5. Thomas, S.; Joseph, K.; Malhotra, S.K.; Goda, K.; Sreekala, M.S. Polymer Composites, Macro-and Microcomposites; John Wiley \& Sons: Hoboken, NJ, USA, 2012.

6. Domina, T.; Koch, K. Consumer reuse and recycling of post-consumer textile waste. J. Fash. Mark. Manag. Int. J. 1999, 3, 346-359. [CrossRef]

7. Brandt, C.C.; Davis, M.R.; Davison, B.; Eaton, L.M.; Efroymson, R.A.; Hilliard, M.R.; Kline, K.; Langholtz, M.H.; Myers, A.; Sokhansanj, S.; et al. 2016 Billion-Ton Report: Advancing Domestic Resources for a Thriving Bioeconomy, Volume 1: Economic Availability of Feedstocks; Office of Scientific and Technical Information (OSTI): Kerela, India, 2016; pp. 1-411.

8. Rowell, R.M.; Stout, H.P. Jute and Kenaf. Handbook of Fiber Chemistry; International Fiber Science and Technology Series; CRC/Taylor \& Francis: Boca Raton, FL, USA, 2007; pp. 409-456. 
9. Roh, H.-G.; Kim, S.; Lee, J.; Park, J. Effect of Low-Temperature Pyrolysis on the Properties of Jute Fiber-Reinforced Acetylated Softwood Kraft Lignin-Based Thermoplastic Polyurethane. Polymers 2018, 10, 1338. [CrossRef]

10. Fink, H.-P.; Weigel, P.; Purz, H.; Ganster, J. Structure formation of regenerated cellulose materials from NMMO-solutions. Prog. Polym. Sci. 2001, 26, 1473-1524. [CrossRef]

11. Ghasemi, M.; Tsianou, M.; Alexandridis, P. Assessment of solvents for cellulose dissolution. Bioresour. Technol. 2017, 228, 330-338. [CrossRef]

12. Gupta, P.; Uniyal, V.; Naithani, S. Polymorphic transformation of cellulose I to cellulose II by alkali pretreatment and urea as an additive. Carbohydr. Polym. 2013, 94, 843-849. [CrossRef]

13. Goswami, P.; Blackburn, R.S.; El-Dessouky, H.M.; Taylor, J.; White, P. Effect of sodium hydroxide pre-treatment on the optical and structural properties of lyocell. Eur. Polym. J. 2009, 45, 455-465. [CrossRef]

14. Raus, V.; Šturcová, A.; Dybal, J.; Šlouf, M.; Vacková, T.; Šálek, P.; Kobera, L.; Vlček, P. Activation of cellulose by 1, 4-dioxane for dissolution in N, N-dimethylacetamide/LiCl. Cellulose 2012, 19, 1893-1906. [CrossRef]

15. Jiang, G.; Huang, W.; Li, L.; Wang, X.; Pang, F.; Zhang, Y.; Wang, H. Structure and properties of regenerated cellulose fibers from different technology processes. Carbohydr. Polym. 2012, 87, 2012-2018. [CrossRef]

16. Isikgor, H.; Remzi, F.; Becer, C. Lignocellulosic biomass: A sustainable platform for the production of bio-based chemicals and polymers. Polym. Chem. 2015, 6, 4497-4559. [CrossRef]

17. Saberi, B.; Chockchaisawasdee, S.; Golding, J.B.; Scarlett, C.J.; Stathopoulos, C.E. Physical and mechanical properties of a new edible film made of pea starch and guar gum as affected by glycols, sugars and polyols. Int. J. Biol. Macromol. 2017, 104, 345-359. [CrossRef] [PubMed]

18. Guerrero, S.J. Antiplasticization and crystallinity in poly(vinyl chloride). Macromolecules 1989, 22, 3480-3485. [CrossRef]

19. Riggleman, R.A.; Douglas, J.F.; De Pablo, J.J. Antiplasticization and the elastic properties of glass-forming polymer liquids. Soft Matter 2009, 6, 292-304. [CrossRef]

20. Stukalin, E.B.; Douglas, J.F.; Freed, K.F. Plasticization and antiplasticization of polymer melts diluted by low molar mass species. J. Chem. Phys. 2010, 132, 084504. [CrossRef]

21. Biswas, M.C.; Bush, B.; Ford, E. Glucaric acid additives for the antiplasticization of fibers wet spun from cellulose acetate/acetic acid/water. Carbohydr. Polym. 2020, 245, 116510. [CrossRef]

22. Lu, C.; Ford, E. Antiplasticizing Behaviors of Glucarate and Lignin Bio-Based Derivatives on the Properties of Gel-Spun Poly(Vinyl Alcohol) Fibers. Macromol. Mater. Eng. 2018, 303, 1700523. [CrossRef]

23. Fengel, D.; Strobel, C. FTIR spectroscopic studies on the heterogeneous transformation of cellulose I into cellulose II. Acta Polym. 1994, 45, 319-324. [CrossRef]

24. Moharram, M.A.; Mahmoud, O.M. FTIR spectroscopic study of the effect of microwave heating on the transformation of cellulose I into cellulose II during mercerization. J. Appl. Polym. Sci. 2007, 107, 30-36. [CrossRef]

25. Jackson, W.J., Jr.; Caldwell, J.R. Antiplasticization. II. Characteristics of antiplasticizers. J. Appl. Polym. Sci. 1967, 11, 211-226. [CrossRef]

26. O'Connor, R.T. Instrumental Analysis of Cotton Cellulose and Modified Cotton Cellulose. 1972. Available online: https: / / www.bcin.ca/bcin/detail.app?id=135910 (accessed on 1 March 2021).

27. Halonen, H.; Larsson, P.T.; Iversen, T. Mercerized cellulose biocomposites: A study of influence of mercerization on cellulose supramolecular structure, water retention value and tensile properties. Cellulose 2013, 20, 57-65. [CrossRef]

28. Nakano, S.; Nakano, T. Morphological changes induced in wood samples by aqueous $\mathrm{NaOH}$ treatment and their effects on the conversion of cellulose I to cellulose II. Holzforschung 2015, 69, 483-491. [CrossRef]

29. Dupont, A.-L.; Tétreault, J. Cellulose degradation in an acetic acid environment. Stud. Conserv. 2000, 45, 201-210.

30. Chen, H. Lignocellulose Biorefinery Engineering: Principles and Applications; Woodhead Publishing: Cambridge, UK, 2015.

31. Miller-Chou, B.A.; Koenig, J.L. A review of polymer dissolution. Prog. Polym. Sci. 2003, 28, 1223-1270. [CrossRef]

32. Lu, C.; Rawat, P.; Louder, N.; Ford, E. Properties and Structural Anisotropy of Gel-Spun Lignin/Poly(Vinyl Alcohol) Fibers Due to Gel Aging. ACS Sustain. Chem. Eng. 2017, 6, 679-689. [CrossRef]

33. Lu, C.; Blackwell, C.; Ren, Q.; Ford, E. Effect of the Coagulation Bath on the Structure and Mechanical Properties of Gel-Spun Lignin/Poly(vinyl alcohol) Fibers. ACS Sustain. Chem. Eng. 2017, 5, 2949-2959. [CrossRef]

34. Zhang, W.-B.; Zhang, Z.-X.; Yang, J.-H.; Huang, T.; Zhang, N.; Zheng, X.-T.; Wang, Y.; Zhou, Z.-W. Largely enhanced thermal conductivity of poly(vinylidene fluoride)/carbon nanotube composites achieved by adding graphene oxide. Carbon 2015, 90, 242-254. [CrossRef]

35. Characteristics of Flax/Linen Fiber. 2018. Available online: https://www.textileschool.com/2632/linen-fiber-from-flax-plantsand-the-linen-fabrics / (accessed on 10 December 2020).

36. McKenna, H.A.; Hearle, J.W.S.; O’Hear, N. Handbook of fibre rope technology. In Handbook of Fibre Rope Technology; Elsevier: Amsterdam, The Netherlands, 2004; pp. 35-74.

37. Properties of Cotton I Cotton Fiber Properties I Cotton Manufacturing. Available online: https://barnhardtcotton.net/technology/ cotton-properties / (accessed on 11 October 2020).

38. Tortora, P.G.; Collier, B.J. Understanding Textiles. 1997. Available online: https://www.bcin.ca/bcin/detail.app?id=179694 (accessed on 13 November 2020). 
39. Hospodarova, V.; Singovszka, E.; Stevulova, N. Characterization of Cellulosic Fibers by FTIR Spectroscopy for Their Further Implementation to Building Materials. Am. J. Anal. Chem. 2018, 9, 303-310. [CrossRef]

40. Dehydration of Alcohols. Available online: https://www.chemguide.co.uk/organicprops/alcohols/dehydration.html (accessed on 11 October 2020).

41. Pană, A.-M.; Rusnac, L.-M.; Bandur, G.; Silion, M.; Deleanu, C.; Balan, M. Novel D-glucose and D-mannose based oligomers: Synthesis and characterization. e-Polymers 2011, 11, 29-42. [CrossRef]

42. Johar, N.; Ahmad, I.; Dufresne, A. Extraction, preparation and characterization of cellulose fibres and nanocrystals from rice husk. Ind. Crop. Prod. 2012, 37, 93-99. [CrossRef]

43. O'sullivan, A.C. The structure slowly unravels. Cellulose 1997, 4, 173-207. [CrossRef]

44. French, A.D. Idealized powder diffraction patterns for cellulose polymorphs. Cellulose 2013, 21, 885-896. [CrossRef]

45. Ford, E.N.J.; Mendon, S.K.; Thames, S.F.; Rawlins, J.W. X-ray diffraction of cotton treated with neutralized vegetable oil-based macromolecular crosslinkers. J. Eng. Fibers Fabr. 2010, 5. [CrossRef] 